\author{
YELLOWSTONE LAKE: \\ AN EVALUATION OF PATTERNS IN PRODUCTIVITY \\ W. H. Romme \\ Department of Biology \\ Fort Lewis College \\ Durango, $\mathrm{CO}$ \\ D. H. Knight \\ Department of Botany \\ University of Wyoming \\ Laramie
}

\title{
Objectives
}

This study was initiated in 1982 to critically evaluate the evidence that primary productivity in Yellowstone Lake has decreased during the last 1500 years with an accelerated decline in the last century. Our specific objectives were the following:

1. Assemble, summarize, and evaluate existing data and observations related to the past and present trophic status of Yellowstone Lake.

2. Identify all possible explanations for the observed pattern in lake productivity, both long-term last 1500 years) and recent last 100 years), and summarize and evaluate existing evidence to support or refute each proposed explanation.

3. Collect new data to test one attractive hypothesis that has been mentioned frequently but never examined closely, namely that changes in the nutrient status and productivity of the lake are related, at least in part, to the effects of large fires in the watershed.

\section{Methods, Results, and Conclusions}

These topics have been summarized in the 1985 Annual Report. We are continuing our larger study of fire history and landscape dynamics in the western portion of the lake watershed with support from the National Science Foundation (see separate report on this project). When this work is completed (hopefully in 1988), we will finish the Yellowstone Lake study and submit a final report on it. 